\title{
Chrysomya megacephala (Fabricius, 1794) (Diptera: Calliphoridae) development by landmark-based geometric morphometrics of cephalopharyngeal skeleton: a preliminary assessment for forensic entomology application
}

\author{
Li-Xuan $\operatorname{Sim}^{1}$ and Raja M. Zuha ${ }^{1,2^{*}}$ (D)
}

\begin{abstract}
Background: Considering the practicality of geometric morphometrics which could discriminate insect species, this application was extended to the analysis of blow fly larval growth based on cephalopharyngeal skeleton. In forensic entomology, cephalopharyngeal skeleton plays a crucial role in species identification but the morphometric information of this part is scarce. In this study, Chrysomya megacephala (Fabricius, 1794) was reared in two study replicates in natural conditions and samplings were conducted at fixed daily intervals. Cephalopharyngeal skeletons were removed from larvae and mounted on glass slides. Images were obtained from the specimens; digitized and geometric morphometric analysis on C. megacephala cephalopharyngeal skeletons was performed with MorphoJ software based on the ordination of five landmarks. The assessments of this analysis were based on centroid size measurements, visualization on the landmarks displacements, classification of the relative landmarks by using canonical variate analysis, and ontogenetic allometry determination.

Findings: Centroid size was strongly correlated with developmental time $(p<0.05)$ and significantly different between daily intervals $(p<0.05)$. Ontogenetic allometric effect based on multivariate regression on Procrustes coordinates and centroid size was significant $(p<0.0001)$, indicating that shape was influenced by growth $(60.3 \%)$. Disposition occurred on all landmarks during development and was further discriminated based on age groups.

Conclusions: Other than discriminating between species, geometric morphometrics was found to be practical to visualize larval growth based on cephalopharyngeal skeletons which can be useful in forensic entomology.
\end{abstract}

Keywords: Forensic entomology, Development, Geometric morphometrics, Centroid size, Allometry, MorphoJ

\footnotetext{
* Correspondence: rmzuha@ukm.edu.my

${ }^{1}$ Forensic Science Programme, Faculty of Health Sciences, Universiti

Kebangsaan Malaysia, Basement One, Tun Seri Lanang Library, 43600 Bangi,

Selangor, Malaysia

${ }^{2}$ Centre for Insect Systematics, Faculty of Science \& Technology, Universiti

Kebangsaan Malaysia, 43600 Bangi, Selangor, Malaysia
} 


\section{Introduction}

In forensic entomology, the age of dipterous larvae, found feeding on decomposing human remains, can be used to estimate minimum post mortem interval (mPMI) . The larval age is estimated based on their growth parameter such as larval body length, which can be inferred from the species-specific developmental model (Sharma et al. 2015). However, there were drawbacks when using larval body length because it can be affected by specimens handling (Tantawi and Greenberg 1993; Adams and Hall 2003; Day and Wallman 2008; Richards et al. 2013) and subsequently lead to inaccuracies in mPMI estimation. Therefore, previous researches suggested cephalopharyngeal skeleton as an alternative growth parameter to larval body length because of its measurement consistency and positive allometry with larval body length (Eliza and Zuha 2018; Rabbani and Zuha 2017). In Calliphoridae larvae, cephalopharyngeal skeleton is the invaginating mouthparts in the cephalic region of the larva, consisting of pharyngeal sclerites and mandibles which are used to facilitate food intake (Teskey 1981). These structures provide vital diagnostic features to identify blow fly species of forensic importance (Greenberg and Kunich 2002) but apparently, the morphometric information of cephalopharyngeal skeleton is still lacking.

In recent years, geometric morphometrics (GM) has been increasingly utilized as a multivariate tool to classify insect species based on morphological shape in both mature and immature stages including flies (Canal et al. 2015; Nuñez and Liria 2016; Nuñez-Rodriguez and Liria 2017a; Tatsuta et al. 2018). GM also provides detailed visualization of morphological transformations and morpho-spatial differences in shape and size unique to species by using shape landmark coordinates, thus providing more accurate species discriminations (Viscosi and Cardini 2011; Cooke and Terhune 2015). In interpreting speciation and sexual dimorphism among flies, adult wing morphology is the most frequently utilized body part (Gidaszewski et al. 2009; Schutze et al. 2012; NuñezRodriguez and Liria 2017b). Apart from discriminating species into phenetic groups, GM also covers ontogenetic allometry which can explain how morphological variation attributes directly to growth (Klingenberg 1998). This scope of application in GM could be useful to describe the growth of forensically important insects.

Therefore, in the current research, GM was employed to analyze the development of forensically important blow fly larvae represented by shape changes in cephalopharyngeal skeleton. Chrysomya megacephala larvae were used as sample, as this species was one of the most prevalent sarcosaprophagous species found at death scenes in Malaysia, Thailand, and the rest of the world (Lee et al.
2004; Sukontason 2005; Sukontason et al. 2008; Kumara et al. 2012; Badenhorst and Villet 2018). Additionally, this species also played a significant role in bacterial and parasitic transmissions in humans (Sulaiman et al. 1988; Sulaiman et al. 1989; Sukontason et al. 2000).

The cephalopharyngeal skeleton shape was profiled based on centroid size, i.e., the square root of the sum of squared distances between each landmark and the centroid of the cephalopharyngeal skeleton (Zelditch et al. 2012). We hypothesized that centroid size correlates with developmental time and varied independently between age groups. The ontogenetic allometry, i.e., the relationship between size and shape across different ages, and visualization of landmark dispositions were also performed by using prescribed methods (Klingenberg 2013; Mitteroecker et al. 2013).

\section{Materials and methods}

This study was conducted in two replicates in natural conditions, i.e., study replicate 1 from 14 August 2018 to 18 August 2018, and study replicate 2 from 24 September 2018 to 29 September 2018.

\section{Sample preparation and species identification}

Chrysomya megacephala eggs were obtained from fresh baits placed in an open area adjacent to Forensic Entomology Laboratory, Forensic Science Program, Universiti Kebangsaan Malaysia, Bangi. Baits consist of approximately $300 \mathrm{~g}$ of fresh fish and cow's liver in a $500-\mathrm{ml}$ plastic container and were placed on the ground. They were left exposed and checked hourly for ovipositon activity by a single female C. megacephala. The adults were identified based on taxonomic descriptions by Kurahashi et al. (1997) while the subsequent larval species were determined based on Barros-Cordeiro and Pujol-Luz (2010) and Sukontason et al. (2008).

A single batch of eggs oviposited by a female $C$. megacephala was collected carefully by using fine-tip forceps and transferred into a rearing container with approximately $30 \mathrm{~g}$ fresh cow's liver as food source. The liver was placed on a 3-cm-thick coarse sawdust and separated by a piece of tissue paper. Eggs were reared overnight at outdoor ambient temperature $\left(23.5-34.0^{\circ} \mathrm{C}\right)$ and relative humidity (RH) (44.0$96.0 \%)$.

On the following day, at 0900 hours, newly emerged first instar larvae were transferred evenly into five freshly prepared rearing containers labeled as day 1 to day 5. They were reared at $27.8 \pm 2.7^{\circ} \mathrm{C}$ and $76.2 \pm$ $7.7 \% \mathrm{RH}$ (first replicate) and $26.1 \pm 1.7^{\circ} \mathrm{C}$ and $81.8 \pm$ $8.9 \% \mathrm{RH}$ (second replicate). Larval sampling was conducted twice at 0900 hours and 1500 hours, per day, based on rearing containers sequence. During each 
sampling occasion, a total of 10 larvae were randomly selected and killed in near-boiling water $\left(\approx 80^{\circ} \mathrm{C}\right)$ for 30-40 s (Amendt et al. 2007). Post-feeding larvae were excluded from sampling.

\section{Sample processing}

Cephalopharyngeal skeleton was obtained by removing larval internal content and adhering tissue in $10 \%$ potassium hydroxide (KOH) (Rabbani and Zuha 2017). The cephalopharyngeal skeleton was subsequently immersed in 10\% acetic acid and $70 \%$ ethanol for 5 min each. Then it was mounted on a glass slide with Berlese Fluid in lateral position, covered with a 5-mm round coverslip. For the first instar larvae, cephalopharyngeal skeletons were mounted directly on the glass slide without $\mathrm{KOH}$ and subsequent treatments because the specimens were too delicate. Cephalopharyngeal skeletons that were not thoroughly cleared or inclined from lateral position were omitted from being used as samples.

\section{Data acquisition and analysis}

Images of cephalopharyngeal skeleton were obtained directly after specimen mounting by using a stereomicroscope (Nikon, Japan) fitted with a 12-megapixel USB3.0 CMOS microscope camera (Toupcam, China). The twodimensional images were then converted to a readable format using tpsUtil (version 1.74) and landmarks were plotted by using tpsDig2 (version 2.31) (download link: http:// life.bio.sunysb.edu/morph/). Landmarks were selected based on geometrical shape of the cephalopharyngeal skeleton, i.e., (1) clipeal arc (anterodorsal process/dorsal bridge), (2) dorsal cornu, (3) concavity of pharyngeal sclerite (tentorial phragma/medial incision), (4) lower ventral cornu, and (5) base of parastomal bar (Nuñez and Liria 2016) (Fig. 1). Geometric morphometric analysis of cephalopharyngeal skeleton was carried out by using MorphoJ software (Klingenberg 2011) (download link: http://www. flywings.org.uk/morphoj_page.htm_), which includes visualization of landmark shifts and canonical variate analysis (CVA) to provide graphical ordination of individuals

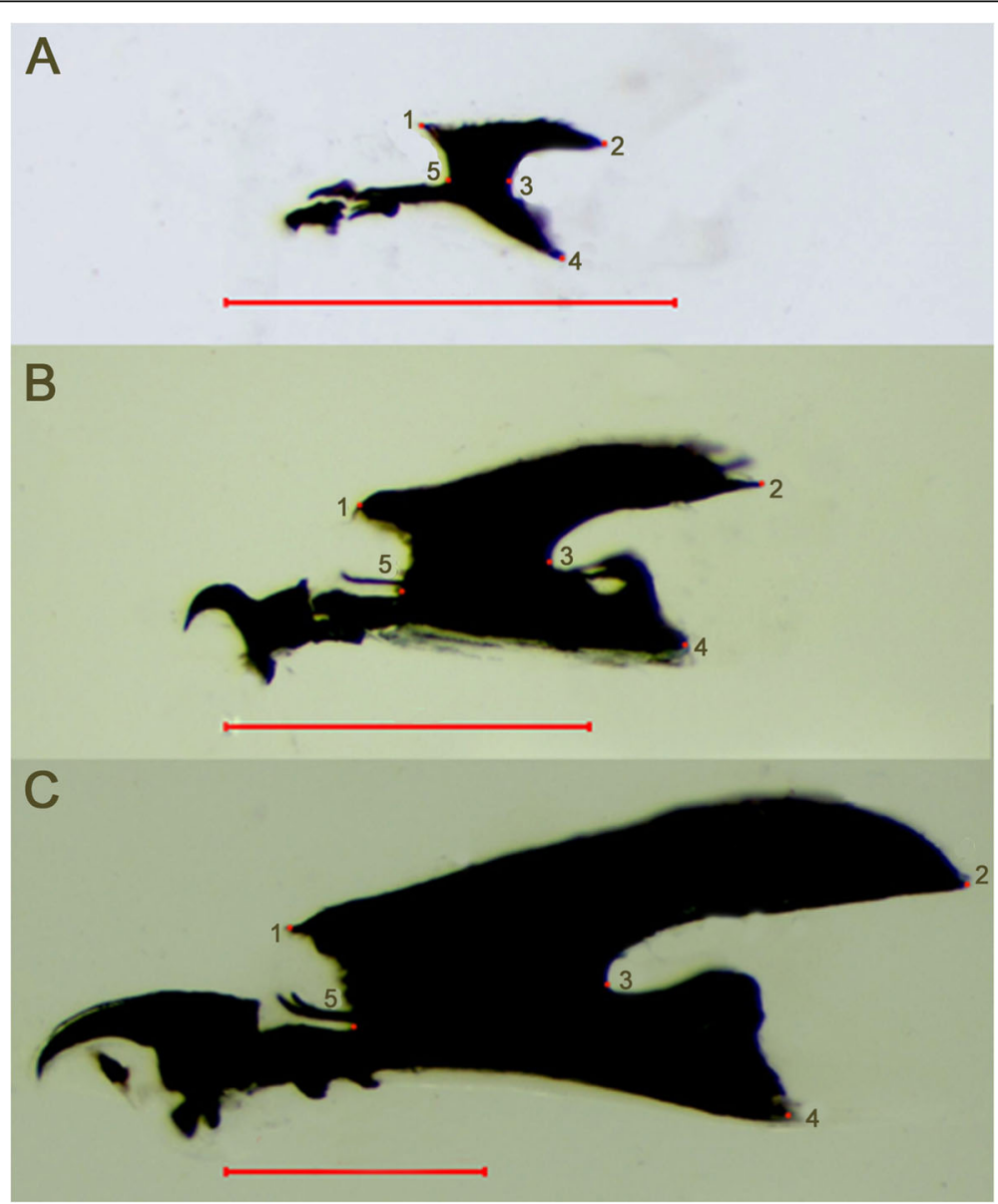

Fig. 1 Geometrical landmarks of C. megacephala cephalopharyngeal skeleton in three different instars. a First instar. b Second instar. c Third instar (bar $=0.5 \mathrm{~mm}$ ). The landmark consist of 1 clipeal arc (anterodorsal process/dorsal bridge), 2 dorsal cornu, 3 concavity of pharyngeal sclerite (tentorial phragma/medial incision), 4 lower ventral cornu, and 5 base of parastomal bar (Nuñez and Liria 2016) (scale bar $=0.5 \mathrm{~mm}$ ) 
Table 1 Descriptive statistics summary of the centroid size of C. megacephala cephalopharyngeal skeletons in study replicates 1 and 2

\begin{tabular}{|c|c|c|c|c|c|c|c|c|}
\hline Replicate & Age group (h) & Mean & Standard deviation & Variance & Min & Max & Range & $N$ \\
\hline \multirow[t]{7}{*}{1} & 20 & 0.19487 & 0.00853 & 0.000 & 0.17939 & 0.20533 & 0.02594 & 10 \\
\hline & 26 & 0.20939 & 0.00517 & 0.000 & 0.19895 & 0.21697 & 0.01802 & 9 \\
\hline & 44 & 0.49301 & 0.02204 & 0.000 & 0.45608 & 0.53149 & 0.07539 & 10 \\
\hline & 50 & 0.48572 & 0.02476 & 0.001 & 0.43375 & 0.51238 & 0.07863 & 8 \\
\hline & 68 & 1.03376 & 0.07173 & 0.005 & 0.89706 & 1.11066 & 0.21350 & 10 \\
\hline & 74 & 1.05578 & 0.03524 & 0.001 & 1.00870 & 1.13109 & 0.12239 & 8 \\
\hline & 92 & 1.12013 & 0.04468 & 0.001 & 1.05996 & 1.19808 & 0.13812 & 8 \\
\hline \multirow[t]{7}{*}{2} & 20 & 0.17959 & 0.01615 & 0.000 & 0.15938 & 0.20099 & 0.04161 & 8 \\
\hline & 26 & 0.19601 & 0.01927 & 0.000 & 0.17253 & 0.22604 & 0.05351 & 10 \\
\hline & 44 & 0.49435 & 0.04156 & 0.002 & 0.41849 & 0.52725 & 0.10575 & 7 \\
\hline & 50 & 0.52639 & 0.01336 & 0.000 & 0.51015 & 0.55445 & 0.04430 & 8 \\
\hline & 68 & 0.80697 & 0.04716 & 0.002 & 0.75632 & 0.88640 & 0.13009 & 7 \\
\hline & 74 & 1.11720 & 0.04639 & 0.002 & 1.04375 & 1.19669 & 0.15294 & 10 \\
\hline & 92 & 1.13567 & 0.03129 & 0.001 & 1.07889 & 1.16663 & 0.08774 & 7 \\
\hline
\end{tabular}

and groups in multidimensional space, followed by cross-validation test in discriminant function analysis (DFA) to classify individuals in separate groups. The regression function in MorphoJ was used to determine ontogenetic allometry which is the influence of size changes on the shape. Prior to morphometric analysis, landmark coordinates were inspected for outliers. In SPSS $^{\mathrm{TM}}$ Version 21 software, centroid sizes were classified based on the larval sampling intervals (age group) as independent groups and they were also checked for normality. They were subsequently analyzed by using one-way analysis of variance (ANOVA) for independent groups $(\alpha=0.05)$. Pearson correlation test was used to determine the significant relationship between centroid size and developmental time.

\section{Results and discussion}

The developmental period of C. megacephala from egg collection until peak feeding the third instar was $92 \mathrm{~h}$ in both study replicates. Based on the conditions of slit on posterior spiracle which could be used to discern larval instars (Barros-Cordeiro and Pujol-Luz 2010), C. megacephala larva was the first instar at 20 and $26 \mathrm{~h}$ and developed to

Table $2 p$ values of pairwise comparisons between age group using Games-Howell post hoc analyses after analysis of variance (ANOVA) for independent groups in study replicates 1 and 2

\begin{tabular}{|c|c|c|c|c|c|c|c|}
\hline \multirow{2}{*}{$\begin{array}{l}\text { Study } \\
\text { replicate }\end{array}$} & \multirow{2}{*}{$\begin{array}{l}\text { Age } \\
\text { group } \\
\text { (h) }\end{array}$} & \multicolumn{6}{|c|}{ Age group (h) } \\
\hline & & 26 & 44 & 50 & 68 & 74 & 92 \\
\hline \multirow[t]{6}{*}{1} & 20 & $<0.0001$ & $<0.0001$ & $<0.0001$ & $<0.0001$ & $<0.0001$ & $<0.0001$ \\
\hline & 26 & & $<0.0001$ & $<0.0001$ & $<0.0001$ & $<0.0001$ & $<0.0001$ \\
\hline & 44 & & & 1.000 & $<0.0001$ & $<0.0001$ & $<0.0001$ \\
\hline & 50 & & & & $<0.0001$ & $<0.0001$ & $<0.0001$ \\
\hline & 68 & & & & & 0.974 & 0.079 \\
\hline & 74 & & & & & & 0.076 \\
\hline \multirow[t]{6}{*}{2} & 20 & 0.470 & $<0.0001$ & $<0.0001$ & $<0.0001$ & $<0.0001$ & $<0.0001$ \\
\hline & 26 & & $<0.0001$ & $<0.0001$ & $<0.0001$ & $<0.0001$ & $<0.0001$ \\
\hline & 44 & & & 0.507 & $<0.0001$ & $<0.0001$ & $<0.0001$ \\
\hline & 50 & & & & $<0.0001$ & $<0.0001$ & $<0.0001$ \\
\hline & 68 & & & & & $<0.0001$ & $<0.0001$ \\
\hline & 74 & & & & & & 0.95 \\
\hline
\end{tabular}




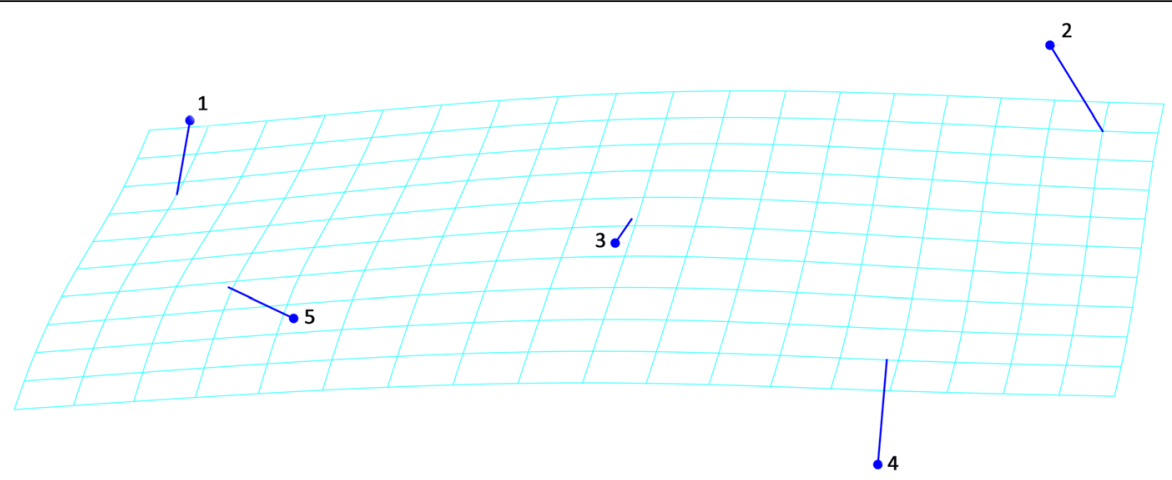

\section{CV1}

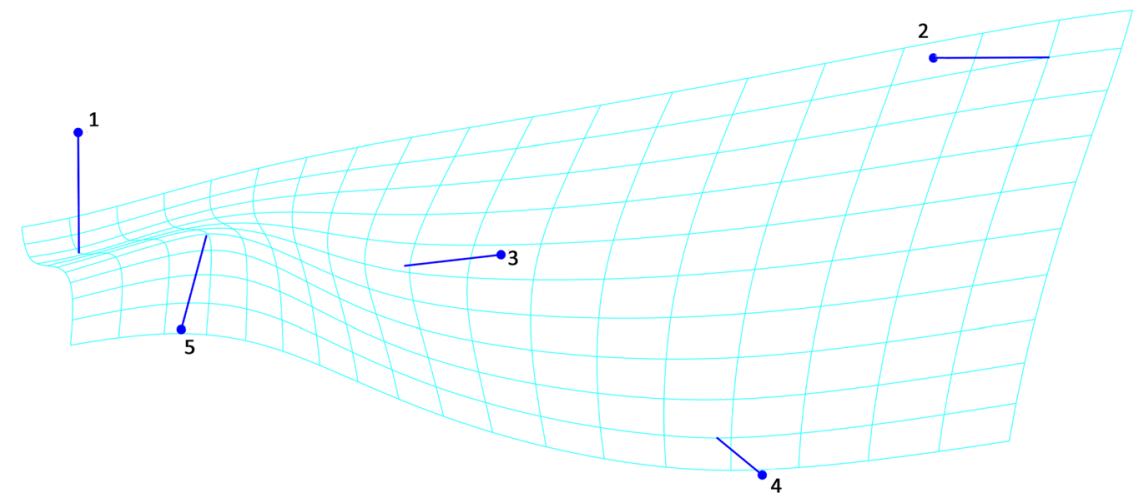

\section{CV2}

Fig. 2 Shape changes associated with CV1 and CV2 on deformed grids in positive directions (scale factor 10.0). The "Iollipop" diagram with dots indicate the average starting shape and the lines are the movement of landmark to the target shape

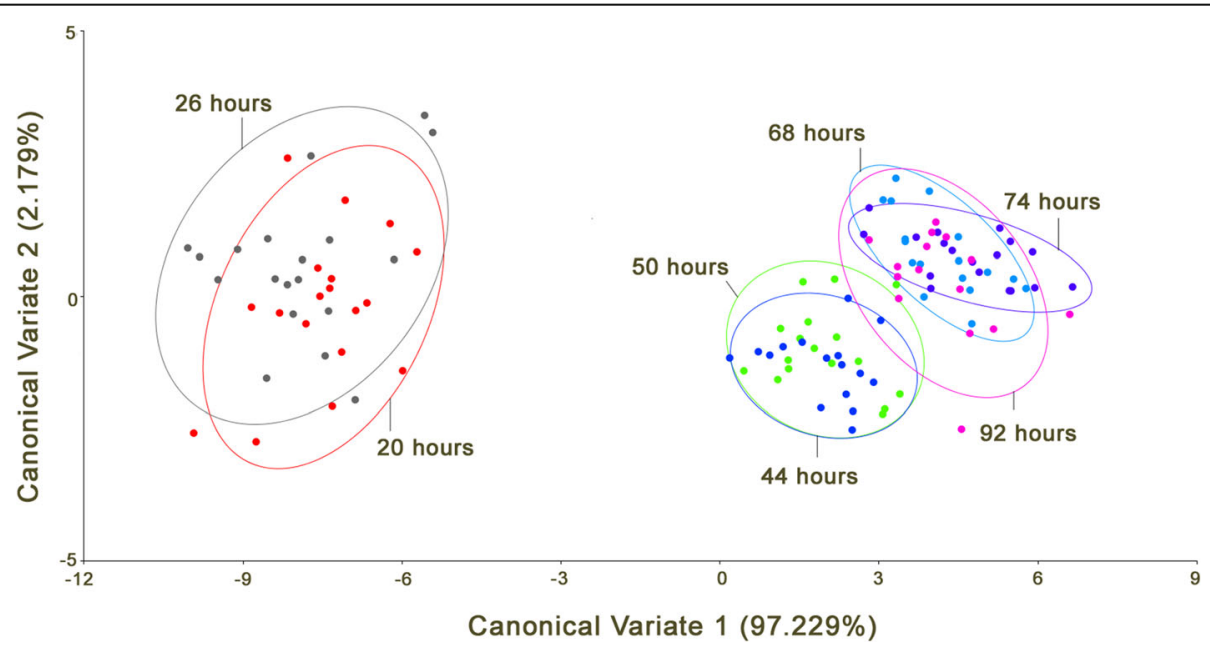

Fig. 3 Scatter plot along CV1 (97.229\%) and CV2 (2.179\%) axes shows the variation in cephalopharyngeal skeleton shapes grouped by equal frequency ellipse $(p=0.9)$. The coordinates are clustered based on the larval-age group sample 
Table 3 Canonical variate analysis (CVA) of C. megacephala cephalopharyngeal skeleton shape given by the Mahalanobis distances (gray boxes) and Procrustes distances (clear boxes). Significant differences are represented by asterisks, i.e., ${ }^{* * *} p<0.0001,{ }^{* *} p<0.01$, ${ }^{*} p<0.05$, while the $p$ value for non-significant differences is indicated in the bracket (permutation 10,000 rounds in MorphoJ)

\begin{tabular}{|c|c|c|c|c|c|c|c|}
\hline Age-group & 20 & 26 & 44 & 50 & 68 & 74 & 92 \\
\hline 20 & - & $\begin{array}{c}0.0386 \\
(P=0.3827)\end{array}$ & $0.1924 * * *$ & $0.1890 * * *$ & $0.2658 * * *$ & $0.2796 * * *$ & $0.2580 * * *$ \\
\hline 26 & $\begin{array}{c}1.2207 \\
(P=0.2697)\end{array}$ & (2) & $0.2125 * * *$ & $0.2108 * * *$ & $0.2839 * * *$ & $0.2986 * * *$ & $0.2775 * * *$ \\
\hline 44 & $9.5345 * * *$ & $10.0145 * * *$ & - & $\begin{array}{c}0.0198 \\
(P=0.5071)\end{array}$ & $0.0886 * * *$ & $0.1065 * * *$ & $0.0862 * * *$ \\
\hline 50 & $9.5229 * * *$ & $10.0468 * * *$ & $\begin{array}{c}0.8199 \\
(P=0.2418)\end{array}$ & - & $0.0923 * * *$ & $0.1074 * * *$ & $0.0854 * * *$ \\
\hline 68 & $11.7312 * * *$ & $12.1014 * * *$ & $2.9225 * * *$ & $3.1292 * * *$ & - & $0.0382 * *$ & $0.0423^{*}$ \\
\hline 74 & $12.2430 * * *$ & $12.6227 * * *$ & $3.2893 * * *$ & $3.4575 * * *$ & $\begin{array}{c}0.8833 \\
(P=0.0649)\end{array}$ & - & $\begin{array}{c}0.0255 \\
(P=0.0713)\end{array}$ \\
\hline 92 & $11.7174 * * *$ & $12.1209 * * *$ & $2.6743 * * *$ & $2.7782 * * *$ & $1.0716^{*}$ & $\begin{array}{c}0.7707 \\
(P=0.1878)\end{array}$ & (2) \\
\hline
\end{tabular}

the second instar at 44 and $50 \mathrm{~h}$ before progressing to the third instar.

Descriptive statistics of cephalopharyngeal skeleton centroid size in both study replicates are summarized in Table 1. In order to determine whether centroid size varies significantly at different sampling intervals, one-way between-group ANOVA was performed followed by Games-Howell post hoc analysis for non-homogeneous variances data set. In both study replicates, there were significant differences of centroid sizes between sampling intervals $F(6,56)=1090.996, p<0.05, \eta^{2}=0.991$ (large effect size) (study replicate 1 ) and $F(6,50)=1219.740, p<0.05$, $\eta^{2}=0.993$ (large effect size) (study replicate 2). Pairwise comparison of centroid sizes between sampling intervals indicated the shape mostly transformed during early developmental stages (Table 2). In replicate 1 , differences were detected between the 44- and 50-h group, 68- and 74-h group, 68- and 92-h group, and 74 and 92-h group.
In replicate 2 , differences were detected between 20 - and 26-h group, 44- and 50-h group, and 74- and 92-h group.

Correlations between centroid size and cephalopharyngeal skeleton developmental time were determined by using Pearson's correlation test. Results indicate a strong significant and positive correlation between centroid size and developmental time with the correlation coefficient, $r$, ranged from 0.964 (study replicate 1) to 0.973 (study replicate 2) $(p<0.05)$. On the ontogenetic allometric effect, regression analysis on the Procrustes coordinates on centroid size among age groups revealed a significant relationship between cephalopharyngeal skeleton shape variation and size (permutation 10,000 rounds in MorphoJ: $p<0.0001$ ). This effect accounted for $60.3 \%$ of the total shape variation. We also performed regression test by using the Procrustes coordinates on log centroid size, resulting $p<0.0001$ with improvement in the effect of the total shape variation of $65.7 \%$.

Table 4 Percentage of correctly classified specimens by cross-validation test in discriminant function analysis (DFA). Significant differences are represented by asterisks, i.e., ${ }^{* * *} p<0.0001$ (permutation 10,000 rounds in MorphoJ). Numbers in brackets represent the number of correctly classified over the total number of specimens

\begin{tabular}{|c|c|c|c|c|c|c|c|}
\hline True assignment to age group & 20 & 26 & 44 & 50 & 68 & 74 & 92 \\
\hline 20 & & $61.11(11 / 18)$ & $100.0^{* * *}(18 / 18)$ & $100.0^{* * *}(18 / 18)$ & $100.0^{* * *}(18 / 18)$ & $100.0^{* * *}(18 / 18)$ & $\begin{array}{l}100.0^{* * *} \\
(18 / 18)\end{array}$ \\
\hline 26 & $47.36(9 / 19)$ & & $100.0^{* * *}(19 / 19)$ & $100.0^{* * *}(19 / 19)$ & $100.0^{* * *}(19 / 19)$ & $100.0^{* * *}(19 / 19)$ & $\begin{array}{l}100.0^{* * *} \\
(19 / 19)\end{array}$ \\
\hline 44 & $100.0^{* * *}(17 / 17)$ & $100.0^{* * *}(17 / 17)$ & & $58.82(10 / 17)$ & $94.12^{* * *}(16 / 17)$ & $94.12^{* * *}(16 / 17)$ & $\begin{array}{l}88.24^{* * *} \\
(15 / 17)\end{array}$ \\
\hline 50 & $100.0^{* * *}(16 / 16)$ & $100.0^{* * *}(16 / 16)$ & $56.25(9 / 16)$ & & $100.0^{* * *}(16 / 16)$ & $100.0^{* * *}(16 / 16)$ & $\begin{array}{l}100.0^{* * *} \\
(16 / 16)\end{array}$ \\
\hline 68 & $100.0^{* * *}(17 / 17)$ & $100.0^{* * *}(17 / 17)$ & $100.0^{* * *}(17 / 17)$ & $100.0^{* * *}(17 / 17)$ & & $52.94(9 / 17)$ & $\begin{array}{l}64.71 \\
(11 / 17)\end{array}$ \\
\hline 74 & $100.0^{* * *}(18 / 18)$ & $100.0^{* * *}(18 / 18)$ & $100.0^{* * *}(18 / 18)$ & $100.0^{* * *}(18 / 18)$ & $72.22(13 / 18)$ & & $\begin{array}{l}72.22 \\
(13 / 18)\end{array}$ \\
\hline 92 & $100.0^{* * *}(15 / 15)$ & $100.0^{* * *}(15 / 15)$ & $86.67^{* * *}(13 / 15)$ & $93.33^{* * *}(14 / 15)$ & $60.0(9 / 15)$ & $53.33(8 / 15)$ & \\
\hline
\end{tabular}


The relationship between centroid size and age in ontogenetic allometry through multivariate regression analysis has been found reliable to explain biological shape changes across different ages including humans (Bulygina et al. 2006; Rodríguez-Mendoza et al. 2011; Mitteroecker et al. 2013; Murta-Fonseca and Fernandes 2016). Based on the results, the centroid size of C. megacephala cephalopharyngeal skeleton was positively correlated with developmental time, indicating the shape transformation occurred along larval progression from the first to the third instar. The transformation of cephalopharyngeal skeleton could be presented in growth trajectory to estimate larval age for $\mathrm{PMI}_{\text {min }}$ analysis based on centroid size. In contrast with its body length, the measurement based on cephalopharyngeal skeleton morphometry was more reliable and consistent to be used as growth parameter in forensic entomology (Rabbani and Zuha 2017; Eliza and Zuha 2018). In addition, these changes explained by the ontogenetic allometry in C. megacephala larva were represented by the cephalopharyngeal skeleton. By using regression analysis of the Procrustes coordinates and centroid size/log-transformed centroid size, the association between shape and size across different age groups was significant with moderate to high effect. This allometric effect has been reported in other organisms and the relationships vary and were usually high during ontogenesis (Rocha et al. 2005; Scalici et al. 2010; Strelin et al. 2018). However, for future studies, we recommend using an equal amount of sample size between groups and to reassess the GM landmarks.

Subsequently, CVA was employed to describe shape variations between age groups by maximizing the effect of separation (Cooke and Terhune 2015). Landmark coordinates of cephalopharyngeal skeletons in study replicates 1 and 2 were pooled and further analyzed on thin-plate spline transformation grid and "lollipop" diagram (scale factor 10.0). Figure 2 displays shape changes along CV1 (97.2\%) axis with landmark 2 (dorsal cornu) and 4 (ventral cornu) displaying the most variation, followed by landmark 1 (anterodorsal process) and 5 (base of parastomal bar). Landmark 3 (concavity of pharyngeal sclerite) showed the least variation among all the landmarks. Along CV2 (2.2\%), landmark 1, 3, and 5 dispositions were amplified.

Shape conformation for cephalopharyngeal skeletons in study replicates 1 and 2 scattered along the first two canonical variate axes (CV1 and CV2) (Fig. 3). The scatter plot from CV1 and CV2 shows that the cephalopharyngeal skeletons of C. megacephala at 20- and 26-h age group was clearly isolated from those at 44- to 92-h group. Mahalanobis and Procrustes distances by pairwise comparisons of all age groups showed significant differences between daily intervals (permutation 10,000 rounds in MorphoJ: $p<0.0001$ ) (Table 3). However, there were no significant differences detected between groups sampled on the same day such as group 20 and $26 \mathrm{~h}$ (day 1), group 44 and $50 \mathrm{~h}$ (day 2), group 68 and 74 h (day 3), and group 74 and $92 \mathrm{~h}$ (day 4). There were also no significant differences between 68 and $74 \mathrm{~h}$ (day 3) with $92 \mathrm{~h}$ (day 4). Cross-validation test in DFA revealed high percentages of correctly classified specimens in all sampling intervals $(86.7-100.0 \% ; p<0.0001)$ except for pairs of 20-26, 44-50, and 68-92 age groups, which corresponded to non-significant results in Mahalanobis and Procrustes distances output (Table 4). Due to the allometric effect, we reran cross-validation test on the groups without the effect of size on the morphological changes by using residuals from multivariate regression analysis (Klingenberg 2016). The result showed similar classifications as in Table 4.

In the present study, the geometric morphometric analysis produced a visual classification of C. megacephala cephalopharyngeal skeletons based on their age groups. CVA was used to display differences among groups that are relative to within-group variation based on multivariate data (Webster and David Sheets 2010). This technique was previously employed in distinguishing insect species and sex, including forensically important blow flies which were attributed by the wing landmarks (Nuñez-Rodiguez and Liria 2017a; Nuñez and Liria 2017b; Sontigun et al. 2017). In adults, a few species of Chrysomya Robineau-Desvoidy 1830, Lucilia RobineauDesvoidy 1830, and Hemipyrellia Townsend 1918 were correctly classified and could be further explained by within genus phenetic relationships (Sontigun et al. 2017) while in the larval stages, Nuñez and Liria (2016) successfully differentiated C. megacephala, Chrysomya albiceps (Wiedemann 1819), and Lucilia cuprina (Wiedemann 1830) by using a similar approach.

Landmark displacements based on the "lollipop" diagram (Fig. 2) served as a visual aid to explain the growth of cephalopharyngeal skeletons. Through visual assessment of these five landmarks on C. megacephala larval development, transformation occurred at all landmarks with the least change on landmark 3 (the concavity of pharyngeal sclerite or medial incision). These changes were consistent with taxonomic descriptions for all three instars (Barros-Cordeiro and Pujol-Luz 2010; Szpila et al. 2013) whereby the deformation of cephalopharyngeal skeleton shape shifted inward based on the selected landmarks.

Landmarks used for cephalopharyngeal skeleton shape description in the present study were limited to five landmarks instead of the eight used by Nuñez and Liria (2016), because of some clearly undeveloped structures in the first instar larvae such as apical hook, union between hypostomal sclerite and the mouth 
hook, and dorsal apodeme of mouth hook. Furthermore, the selection of landmarks for GM analysis adhered to the criteria that they can be found repeatedly and not difficult to locate (Bookstein 1991; Zelditch et al. 2012) while at the same time needs to adequately cover the morphology of the subject. A matter of concern that demands further investigation is the coplanarity of landmarks on cephalopharyngeal skeleton, as the actual three-dimensional shape could have been distorted when projected as a two-dimensional image. To minimize this effect, we removed any obscure landmarks when using a two-dimensional image of cephalopharyngeal skeleton as a sample. Images were also taken in a similar plane by using fixed focal length and lighting. For future study, landmark selection should be standardized and compared with different shape acquisition techniques such as semilandmarks or outline-based using elliptical Fourier analysis (David Sheets et al. 2006; Gunz and Mitteroecker 2013; Changbunjong et al. 2016; Santillán-Guayasamín et al. 2017) or 3D morphometrics (Bai and Yang 2014). It is also possible to tilt the cephalopharyngeal skeleton form dorsally or ventrally to explore shape variation as object symmetry (Klingenberg 2002), i.e., the alternate view to asymmetrical lateral shape as in the current study.

\section{Conclusions}

GM analysis on C. megacephala cephalopharyngeal skeleton can be useful to discriminate larval age group and aid growth visualization based on landmark displacements. Correlation between centroid size of C. megacephala cephalopharyngeal skeleton and developmental time indicated that it can be used as a growth parameter which could be applicable for mPMI estimation. Given the results from the present study, GM analysis on cephalopharyngeal skeleton shape variation merit further exploratory investigations, especially in comparing different forensically important fly species and by using different environmental settings such as rearing temperatures and food sources as these could also influence the biological shape (Dujardin 2008; Gobbi et al. 2013).

\section{Abbreviations}

CVA: Canonical variate analysis; DFA: Discriminant function analysis; GM: Geometric morphometrics; RH: Relative humidity

\section{Acknowledgements}

The authors would like to thank laboratory staffs from Forensic Science Program, Faculty of Health Sciences, UKM, for providing the equipment and chemicals required. We also wish to thank Ms. Sharifah Shakilah Abdullah for her kind assistance during research.

\section{Authors' contributions}

LXS and RMZ conducted the research and organized the structure of the manuscript. Both authors read and approved the final manuscript.
Funding

This research was funded by UKM Research Incentive Grant: GGP-2017-036.

Availability of data and materials

Please contact the author for data requests.

Ethics approval and consent to participate

Not applicable.

\section{Consent for publication}

Not applicable.

\section{Competing interests}

The authors declare that they have no competing interests.

Received: 18 February 2019 Accepted: 10 September 2019

Published online: 27 October 2019

\section{References}

Adams ZJO, Hall MJR (2003) Methods used for the killing and preservation of blowfly larvae, and their effect on post-mortem larval length. Forensic Sci Int 138:50-61. https://doi.org/10.1016/j.forsciint.2003.08.010

Amendt J, Campobasso CP, Gaudry E, Reiter C, LeBlanc HN, Hall MJR (2007) Best practice in forensic entomology-standards and guidelines. Int J Legal Med 121(2):90-104. https://doi.org/10.1007/s00414-006-0086-x

Badenhorst R, Villet MH (2018) The uses of Chrysomya megacephala (Fabricius, 1794) (Diptera: Calliphoridae) in forensic entomology. Forensic Sci Res 3(1):2-15. https://doi.org/10.1080/20961790.2018.1426136

Bai M, Yang X (2014) A review of three-dimensional (3D) geometric morphometrics and its application in entomology. Acta Entomol Sinica 57(9):1105-1111

Barros-Cordeiro KB, Pujol-Luz JS (2010) Morfologia e duração do desenvolvimento pós-embrionário de Chrysomya megacephala (Diptera: Calliphoridae) em condições de laboratório. Pap Avulsos Zool 50(47):709-717. https://doi.org/10. 1590/S0031-10492010004700001

Bookstein FL (1991) Morphometric tools for landmark data: geometry and biology. Cambridge University Press, Cambridge

Bulygina E, Mitteroecker P, Aiello L (2006) Ontogeny of facial dimorphism and patterns of individual development within one human population. Am J Phys Anthropol 131:432-443. https://doi.org/10.1002/ajpa.20317

Canal NA, Hernández-Ortiz V, Tigrero Salas JO, Selivon D (2015) Morphometric study of third-instar larvae from five morphotypes of the Anastepha fraterculus cryptic species complex (Diptera, Tephritidae). Zookeys 540:41-59. https://doi.org/10.3897/szookeys.540.6012

Changbunjong T, Sumruayphol S, Weluwanarak T, Ruangsittichai J, Dujardin JP (2016) Landmark and outline-based geometric morphometrics analysis of three Stomoxys flies (Diptera: Muscidae). Folio Parasit 63(037). https://doi.org/ 10.14411/fp.2016.037

Cooke SB, Terhune CE (2015) Form, function and geometric morphometrics. Anat Rec 298:5-28. https://doi.org/10.1002/ar.23065

David Sheets H, Covino KM, Panasiewicz JM, Morris SR (2006) Comparison of geometric morphometric outline methods in the discrimination of age-related differences in feather shape. Front Zool 3(15). https://doi. org/10.1186/1742-9994-3-15

Day DM, Wallman JF (2008) Effect of preservative solutions on preservation of Calliphora augur and Lucilia cuprina larvae (Diptera: Calliphoridae) with implications for post-mortem interval estimates. Forensic Sci Int 179(1):1-10. https://doi.org/10.1016/j.forsciint.2008.04.006

Dujardin JP (2008) Morphometrics applied to medical entomology. Infect Genet Evol 8(6):875-890. https://doi.org/10.1016/j.meegid.2008.07.011

Eliza P, Zuha RM (2018) Preliminary assessment of cephalopharyngeal skeleton length and body length of Hemipyrellia ligurriens (Wiedermann) (Diptera: Calliphoridae) larvae as potential parameters to estimate minimum post mortem interval. Egypt J Forensic Sci 8(39). https://doi. org/10.1186/s41935-018-0070-x

Gidaszewski NA, Baylac M, Klingenberg CP (2009) Evolution of sexual dimorphism of wing shape in the Drosophila melanogaster subgroup. BMC Evol Biol 9:110. https://doi.org/10.1186/1471-2148-9-110

Gobbi P, Martínez-Sánchez A, Rojo S (2013) The effects of lanval diet on adult life-history traits of the black soldier fly, Hermetia illucens (Diptera: Stratiomyidae). Eur J Entomol 110(3):461-468. https://doi.org/10.14411/eje.2013.061 
Greenberg B, Kunich JC (2002) Entomology and the law: flies as forensic indicators. Cambridge University Press, Cambridge

Gunz P, Mitteroecker P (2013) Semilandmarks: a method for quantifying curves and surfaces. Hystrix It J Mamm 24(1):103-109. https://doi.org/10. 4404/hystrix-24.1-6292

Klingenberg CP (1998) Heterochrony and allometry: the analysis of evolutionary change in ontogeny. Biol Rev 73:79-123. https://doi.org/10. 1111/j.1469-185X.1997.tb00026.x

Klingenberg CP (2002) Shape analysis of symmetric structures: quantifying variation among individuals and asymmetry. Evolution 56(10):1909-1920. https://doi.org/10.1111/j.0014-3820.2002.tb00117.x

Klingenberg CP (2011) MorphoJ: an integrated software package for geometric morphometrics. Mol Ecol Resour 11(2):353-357. https://doi.org/10.1111/j. 1755-0998.2010.02924.x

Klingenberg CP (2013) Visualizations in geometric morphometrics: how to read and how to make graphs showing shape changes. Hystrix It J Mamm 24(1): 15-24. https://doi.org/10.4404/hystrix-24.1-7691

Klingenberg CP (2016) Size, shape, and form: concepts of allometry in geometric morphometrics. Dev Genes Evol 226:113-137. https://doi.org/10.1007/s00427 016-0539-2

Kumara TK, Disney RHL, Abu Hassan A, Flores M, Hwa TS, Mohamed Z, Che Salmah M, Bhupinder S (2012) Occurrence of oriental flies associated with indoor and outdoor human remains in tropical climate of North Malaysia. J Vector Ecol 37(1):62-68. https://doi.org/10.1111/j.1948-7134.2012.00200.x

Kurahashi H, Benjaphong N, Omar B (1997) Blow flies (Insecta: Diptera: Calliphoridae) of Malaysia and Singapore. Raffles Bull Zool Supp No. 5:1-88

Lee HL, Krishnasamy M, Abdullah AG, Jeffery J (2004) Review of forensically important entomological specimens in the period of 1972-2002. Trop Biomed 21(2):69-75

Mitteroecker P, Gunz P, Windhager S, Schaefer K (2013) A brief review of shape, form, and allometry in geometric morphometrics, with applications to human facial morphology. Hystrix It J Mamm 24(1):59-66. https://doi.org/10. 4404/hystrix-24.1-6369

Murta-Fonseca RA, Fernandes DS (2016) The skull of Hydrodynastes gigas (Duméril, Bibron \& Duméril, 1854) (Serpentes: Dipsadidae) as a model of snake ontogenetic allometry inferred by geometric morphometrics. Zoomorphology 135(2):233-241. https://doi.org/10.1007/s00435-015-0297-0

Nuñez J, Liria J (2016) Cephalopharyngeal geometric morphometrics in three blowfly species (Diptera: Calliphoridae). J Entomol and Zool Stud 4(1):338-341

Nuñez-Rodriguez J, Liria J (2017b) Sexual wing shape dimorphism in Piophila casei (Linneaus, 1758 Diptera: Piophilidae). Indian J For Med Toxicol 11(2): 217-221. https://doi.org/10.5958/0973-9130.2017.00100.1

Nuñez-Rodriguez JA, Liria J (2017a) Geometric morphometrics sexual dimorphism in three forensically-important species of blow fly (Diptera: Calliphoridae). LEB 4(4):272-284

Rabbani A, Zuha RM (2017) Cephalopharyngeal skeleton morphometry of Hypopygiopsis violacea (Macquart) (Diptera: Calliphoridae) - a preliminary assessment for its application in forensic entomology. J Entomol and Zool Stud 5(1):777-782

Richards CS, Rowlinson CC, Hall MJR (2013) Effects of storage temperature on the change in size of Calliphora vicina larvae during preservation in $80 \%$ ethanol. Int J Legal Med 127(1):231-241. https://doi.org/10.1007/s00414-012-0683-9

Rocha DS, Patterson JS, Sandoval CM, Jurberg J, Ângulo VM, Esteban AM, Galvão C (2005) Description and ontogenetic morphometrics on nymphs of Belminus herreri Lent \& Wygodzinsky (Hemiptera: Reduviidae, Triatominae). Neotrop Entomol 34(3):491-497. https://doi.org/10.1590/S1519566×2005000300019

Rodríguez-Mendoza R, Muñoz M, Saborido-Rey F (2011) Ontogenetic allometry of the bluemouth, Helicolenus dactylopterus dactylopterus (Teleostei: Scorpaenidae), in the Northeast Atlantic and Mediterranean based on geometric morphometrics. Hydrobiologia 670:5-22. https://doi.org/10.1007/s10750-011-0675-7

Santillán-Guayasamín S, Villacís AG, Grijalva MJ, Dujardin JP (2017) The modern morphometric approach to identify eggs of Triatominae. Parasite Vector 10(55). https://doi.org/10.1186/s13071-017-1982-2

Scalici M, Macale D, Gibertini G (2010) Allometry in the ontogenesis of Austropotamobius pallipes species complex (Decapoda: Astacidae): the use of geometric morphometrics. Ital J Zool 77(3):296-302. https://doi.org/10.1080/ 11250000903039794

Schutze MK, Jessup A, Clarke AR (2012) Wing shape as a potential discriminator of morphologically similar pest taxa between the Bactrocera dorsalis species complex (Diptera: Tephritidae). B Entomol Res 102(1):103-111. https://doi. org/10.1017/S0007485311000423
Sharma R, Garg RK, Gaur JR (2015) Various methods for the estimation of the post mortem interval from Calliphoridae: a review. Egypt J For Sci 5(1):1-12. https://doi.org/10.1016/j.ejfs.2013.04.002

Sontigun N, Sukontason KL, Zajac BK, Zehner R, Sukontason K, Wannasan A, Amendt J (2017) Wing morphometrics as a tool in species identification of forensically important blow flies of Thailand. Parasite Vector 10(229). https:/doi.org/10.1186/ s13071-017-2163-z

Strelin MM, Benitez-Vieyra S, Fornoni J, Klingenberg CP, Cocucci A (2018) The evolution of floral ontogenetic allometry in the Andean genus Caiophora (Loasaceae, subfam. Loasoideae). Evol Dev 20:29-39. https://doi.org/10.1111/ede.12246

Sukontason K, Bunchoo M, Khantawa B, Pianjai S, Sukontason K, Methanitikorn R, Rongsriyam Y (2000) Mechanical carrier of bacterial enteric pathogens by Chrysomya megacephala (Diptera: Calliphoridae) in Chiang Mai, Thailand. Southeast Asian J Trop Med Public Health 31(Suppl 1):157-161

Sukontason K, Piangjai S, Siriwattanarungsee S, Sukontason KL (2008) Morphology and developmental rate of blow flies Chrysomya megacephala and Chrysomya rufifacies in Thailand: application in forensic entomology. Parasitol Res 102(6):1207-1206. https://doi.org/10.1007/s00436-008-0895-6

Sukontason KL (2005) Forensically important fly maggots in a floating corpse: the first case report in Thailand. J Med Assoc Thai 88(10):1458-1460

Sulaiman S, Sohadi AR, Jeffery J (1989) Human helminth parasite burdens on cyclorrhaphan flies (Diptera) trapped at aboriginal settlement in Malaysia. Bull Ent Res 79(4):625-629. https://doi.org/10.1017/S0007485300018770

Sulaiman S, Sohadi AR, Yunus H, Iberahim R (1988) The role of some cyclorrhaphan flies as carriers in Malaysia. Med Vet Entomol 2:1):1-1):6. https://doi.org/10.1111/j.1365-2915.1988.tb00043.x

Szpila K, Hall MJR, Sukontason KL, Tantawi TI (2013) Morphology and identification of first instars of the European and Mediterranean blowflies of forensic importance. Med Vet Entomol 27:181-193. https://doi.org/10.1111/j. 1365-2915.2012.01030.x

Tantawi TI, Greenberg B (1993) The effect of killing and preservative solutions on estimates of maggot age in forensic cases. J Forensic Sci 38(3):702-707

Tatsuta H, Takahashi KH, Sakamaki Y (2018) Geometric morphometrics in entomology: basics and applications. Entomol Sci 21:164-168. https://doi. org/10.1111/ens.12293

Teskey HJ (1981) Morphology and terminology - larvae. In: McAlpine JF, Peterson BV, Shewell GE, Teskey HJ, Vockeroth JR, Wood DM (eds) Manual of Nearctic Diptera, vol 1. Minister of Supply and Services Canada, Quebec, pp 74-77

Viscosi V, Cardini A (2011) Leaf morphology, taxonomy and geometric morphometrics: a simplified protocol for beginners. Plos One 6(10):e25630. https://doi.org/10.1371/journal.pone.0025630

Webster M, David Sheets H (2010) A practical introduction to landmark-based geometric morphometrics. The Paleontological Society Papers 16:163-188. https://doi.org/10.1017/S1089332600001868

Zelditch ML, Swiderski DL, David Sheets H (2012) Geometric morphometrics for biologists: a primer, 2nd edn. Academic Press, London

\section{Publisher's Note}

Springer Nature remains neutral with regard to jurisdictional claims in published maps and institutional affiliations.

\section{Submit your manuscript to a SpringerOpen ${ }^{\circ}$ journal and benefit from:}

- Convenient online submission

- Rigorous peer review

- Open access: articles freely available online

- High visibility within the field

- Retaining the copyright to your article

Submit your next manuscript at $>$ springeropen.com 